\title{
INFORMATION SECURITY AND DATA PRIVACY FOR THE AUDIOVISUAL MARKET - CYBER SECURITY
}

\section{Chair: EMERSON WEIRICH, Gerente Executivo de Engenharia da EBC}

After the digitization of the Audiovisual market, developing correctly the strategies of Information Security and Data Privacy is not an expense but an obligatory investment. Currently audio and video files are distributed on different platforms and on different devices, especially with the expected growth of loT (Internet of Things) where media devices multiply and the risks increase proportionally. It is a constant monitoring of threats, vulnerabilities, risks, sensitivities and impacts, in order to allow adequate sizing and modeling of solutions. In this session, experts on the subject will discuss not only the security of data and information, but also that of the systems themselves.

- INTERNET OF THINGS: A VIEW OF THE CYBER SECURITY CHALLENGES IN THE MEDIA AND ENTERTAINMENT INDUSTRY Speaker: Leandro Valente, Especialista em Segurança da Informação - TV Globo

The main objective of this lecture is to demonstrate an executive view of the main cyber security risks related to loT devices, focusing on the media and entertainment sector, exposing how cyber attacks can harm this industry by discussing real cases of attacks Involving companies in this sector. In addition, loT-focused market frameworks, best practices and the main challenges in implementing these will be exposed..

- THE HUMAN FACTOR IN INFORMATION PROTECTION Speaker: Vinícius Brasileiro, Supervisor Executivo de Segurança da Informação - TV Globo

With the advancement of technologies and protection tools, criminals direct their actions to a factor little worked by the organizations: the behavior and the attitude of the collaborators regarding the security of the information. Learn about the main forms of this type of approach, protection models and techniques, and how to build a safety culture. 
- INFORMATION SECURITY STRATEGIES IN DIGITAL MEDIA COMPANIES AND CORPORATE RISK MANAGEMENT.

\section{Speaker: Tácito Augusto Silva Leite, Diretor - T-Risk Método de avaliação de Riscos}

Important digital media companies have already suffered cyber attacks on their information electronic basis causing millionaire losses. The media industry is increasingly exposed to the threats posed by its main assets - video and audio - that now travel in the digital information world. Risk assessment should be integrated and involve the various sectors of organizations. Proper controls, to be efficient, should strike a balance between technology, processes and people. To minimize exposure of organizations to the risks of the digital world, it is desirable to adopt consistent information security policies in addition to awareness training for all involved.

- IOT BOTNETS: "THINGS" TO ATTACK..

\section{Speaker: Lucimara Desiderá - Analista de Segurança - CERT.br/NIC.br}

The Internet of Things (IoT) is already a reality and the entertainment industry makes use of several connected devices such as cameras, drones, TVs, antennas, wi-fi routers, etc. Most loT devices are not designed with safety in mind. To a large extent, the hardware industry does not have the software security view and repeats primary errors that lead to the production of vulnerable devices that are "recruited" by criminals for malicious purposes such as denial of service attacks. Such attacks can reach large scales and severely impact the operation of online entertainment (such as streaming, games, polls). This presentation will discuss technical security issues related to loT, how botnets abusing loT, including statistics of infected devices, and some measures to improve the scenario.

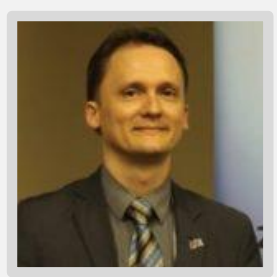

EMERSON WEIRICH, Gerente Executivo de Engenharia da EBC

Emerson Weirich is the director of the SET Center-West Region. He is the current executive manager of Engineering of Empresa Brasil de Comunicação (TV Brasil, TV NBR, Radios Nacional and Radios MEC ). He have a master in Science and Technology Management, a specialist in Strategic Management of Technology and has worked in several communication companies in Brazil (RBS, TVE, Radiobrás e TV Justiça).

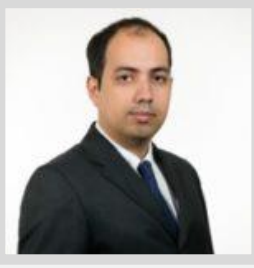

Leandro Valente, Especialista em Segurança da Informação - TV Globo

Leandro Valente has 13 years of experience in information security and has already been part of the security team of large companies in the market, such as Arcon / NEC, Oi Telecomunicações, Ernst \& Young and is currently part of TV Globo's information security projects team. He is CISSP certified and is currently studying for an MBA in Business Management at IBMEC. 

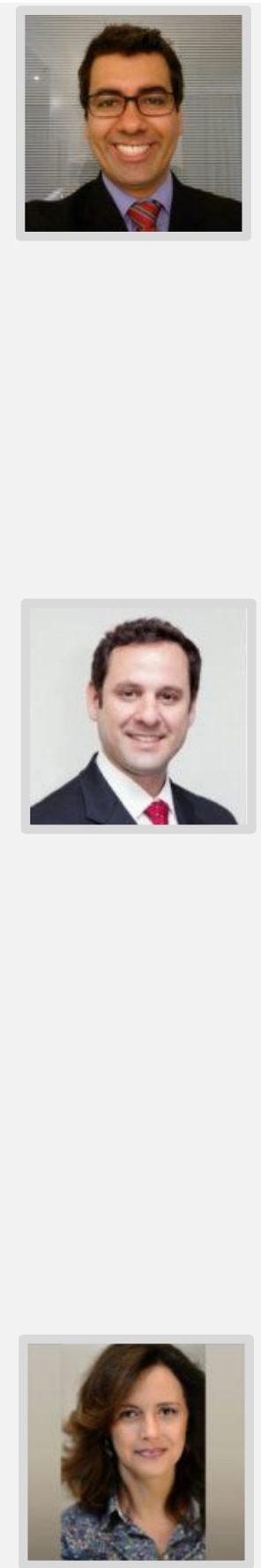

\section{Vinícius Brasileiro, Supervisor Executivo de Segurança da Informação - TV Globo}

Vinicius has 15 years of experience in auditing systems and business processes, information security, business continuity, process mapping, internal controls, corporate risk management and compliance. He holds a degree in Computer Science and Accounting from Estácio de Sá University and a post-graduate degree in IT Auditing from Estácio de Sá University. Certified Information Systems Auditor (CISA), Certified Information Security Manager (CISM) and ISACA Certified in Risk and Information System Control (CRISC); Certified Chief Information Security Officer (C | CISO) by EC-Council; Lead Auditor in Information Security Management System (ISO 27001 LA) by BSI; Information Security Management Advanced based on ISO / IEC 27002 (ISMAS) by EXIN. He is a Member of the Special Risk Management Study Committee and the Information Technology Study Committee - Security Techniques of the Brazilian Computer and Data Processing Committee at ABNT.

\section{Tácito Augusto Silva Leite, Diretor - T-Risk Método de avaliação de Riscos}

He has been working in the area of security and risk management since 1994, developing activities of integrated risk management, loss prevention, global security projects and administration of security companies. Director of the Brazilian Association of Security Professionals, author of the book Gestão de Riscos na Segurança Patrimonial consultoriadeseguranca.com.br, creator of Total Risk method and the platform totalrisk.com.br, organizer of the bibliotecadeseguranca.com.br, coauthor of the 1st and the 2nd ABSEG Business Security Collection. Postgraduate in Business Security from Universidad Pontificia Comillas in Madrid, MBA in Business Security Management from Universidade Anhembi-Morumb, MBA in Information Systems from UnP with in-depth information security, Training named Gestão de Recursos de Defesa by the Escola Superior de Guerra - ESG, Course on Risk Management and Audit Based on ISO 31000 by the QSP and Officer of the Reserve of the Brazilian Army. Has the DSE certification by UPCO - Spain, ASE by ADESG-ABSEG and Certified ISO 31000 Risk Management Professional by The Global Institute G31000 \& International Accreditation Board for Risk Management, Geneva, Switzerland.

\section{Lucimara Desiderá - Analista de Segurança - CERT.br/NIC.br}

Lucimara Desiderá is a Security Analyst at CERT.br/NIC.br, where she focuses on the areas of Outreach and Internet Security Awareness. Its activities include developing materials related to good security practices, delivering lectures and workshops, organizing conferences, working in cooperation with other incident response teams, with international forums (such as LACNIC, LACNOG, FIRST, M3AAWG) and with different Internet sectors in Brazil. She is also the cofounder and coordinator of the Anti-Abuse Working Group for Latin America and the Caribbean (LAC-AAWG). He holds a Master's Degree in Electrical Engineering from UNICAMP and CISSP.

Cite this article:

Weirich, E., V., Leandro, Brasileiro, V., Leite, T. A. . and Desiderá, L.; 2017. Information Security and Data Privacy for the Audiovisual Market - Cyber Security. ISSN Print: 2447-0481. ISSN Online: 2447-049X. v.3. doi: 10.18580/setep.2017.6. Web Link: http://dx.doi.org/10.18580/setep.2017.6 